DE

M E D I C I N A

T R O P I C A L

$\mathrm{DE}$

SÃO PAULO

JOURNAL OF THE SÃO PAULO INSTITUTE OF TROPICAL MEDICINE

(1)Fundação Amaral Carvalho, Serviço de Transplante de Medula Óssea, Jaú, São Paulo, Brazil

(2)Universidade de São Paulo, Instituto de Medicina Tropical de São Paulo, Laboratório de Virologia, LIM52, São Paulo, São Paulo, Brazil

Correspondence to: Paula Moreira da Silva

Fundação Amaral Carvalho, Serviço de Transplante de Medula Óssea,Travessa Coronel Ricardo Auler, 457, Vila Assis, CEP 17210-200, Jaú, SP, Brazil

Tel: +5514 3602-1381

E-mail: pauladc@gmail.com

Received: 8 March 2017

Accepted: 27 July 2017

\section{Difficulties in the revaccination program of hematopoietic stem cell transplantation recipients}

Paula Moreira da Silva ${ }^{1}$, Élen Monteiro da Silva ${ }^{1}$, Anderson João Simioni ${ }^{1}$, Mair Pedro de Souza', Vergílio Antonio Rensi Colturato', Clarisse Martins Machado ${ }^{1,2}$

\section{ABSTRACT}

Hematopoietic stem cell transplant (HSCT) recipients should be routinely revaccinated after transplantation. We evaluated the difficulties met in the revaccination program and how a prospective and tailored follow-up could help to overcome these obstacles. HSCT recipients $(n=122)$ were prospectively followed up and categorized into Group $1(n=72)$, recipients who had already started the revaccination program, and Group $2(n=50)$, recipients starting their vaccines. Whenever a difficulty was reported, interventions and subsequent evaluations were performed. Reported problems were related to patient compliance, HSCT center and/ or vaccination center. Problems related to patient compliance were less frequent than those related to HSCT center modifications of previous recommendations, or to errors made by the vaccination center. The main gap found was vaccination delays (81.9\%). Advisory intervention was needed in $64 \%$ and $46 \%$ of Group 1 and Group 2, respectively ( $p=0.05)$, and was partially successful in around $70 \%$ of the cases. Total resolution was achieved in more than $35 \%$ in both groups. Improvements are needed in the Brazilian vaccination program for HSCT recipients to assure a complete and updated revaccination schedule. HSCT centers should assign nurses and transplant infectious disease specialist physicians to organize the revaccination schedule and to monitor the program development.

KEYWORDS: Hematopoietic stem cell transplantation. Immunization. Difficulties in revaccination

\section{INTRODUCTION}

After hematopoietic stem cell transplantation (HSCT), a temporary state of combined immunodeficiency occurs, with gradual recovery of humoral and cellular immunity during the early years of transplantation ${ }^{1}$. The immunodeficiency state places the recipient at an increased risk for a variety of pathogens, some of which may be prevented by immunization ${ }^{2-4}$.

Antibody titers to vaccine-preventable diseases, such as tetanus, diphtheria, polio, or measles, decrease from one to ten years after $\mathrm{HSCT}^{5-8}$. Therefore, a revaccination program is recommended for both allogeneic and autologous HSCT recipients ${ }^{2,9-11}$.

The difference between the ideal scenario presented in guidelines and reallife scenarios is one of the most recognized barriers to the implementation of recommended practices ${ }^{12}$. Brazil has a national immunization program, which guarantees full and free access for all population. Through the National Immunization Program, the Brazilian Ministry of Health offers a free vaccination program for immunocompromised patients managed by the Reference Centers for Special 
Immunobiologicals (CRIE), spread regionally across the country. Despite the excellence of the revaccination program, several pitfalls have been observed over the years.

The present study aimed to demonstrate the pitfalls found in the post-HSCT revaccination process, and how a prospective and tailored follow-up developed by a specialized nurse and a transplant infectious disease specialist physician may help to overcome such obstacles.

\section{MATERIAL AND METHODS}

The study was conducted at the outpatient facility of the HSCT Program of Amaral Carvalho Foundation (ACF), in the city of Jahu, São Paulo State, Brazil from January to December 2014.

\section{Population}

Patients from all States of Brazil are referred to our center to undergo HSCT. One hundred and thirty patients were invited to participate in the study and signed the informed consent. Three patients were excluded due to death or relapse of the underlying disease before starting the revaccination protocol, and five patients due to lack of compliance with the study follow-up. Thus, 122 HSCT recipients were analyzed.

\section{Revaccination Program}

The revaccination program begins around the fourth month of transplantation and, generally, all patients return to their hometowns to start vaccines locally. Live attenuated vaccines are started only after the second year of HSCT in patients not receiving immunosuppressive drugs. Table 1 shows the revaccination schedule proposed by the Amaral Carvalho Foundation HSCT center, and Table 2 shows the $\mathrm{CRIE}^{13}$ and the IDSA Guidelines schedule ${ }^{14}$.

\section{Study design}

Quantitative, non-randomized and single-center study, including two cohorts of patients: Group 1) patients who had already initiated the revaccination process; Group 2) patients who were close to start the program. Group 1 consisted of 72 HSCT recipients (59\%), at a median of 363 days after HSCT (range 106-722), who had already started the revaccination program. After signing the informed consent, patients were questioned about the difficulties related to the revaccination program. Then, their vaccination cards were compared to the local protocol and designated as appropriate or not, according to the time after vaccination start. After this initial retrospective evaluation, patients from Group 1 were prospectively followed up until the

Table 1 - HSCT revaccination schedule at Amaral Carvalho Foundation

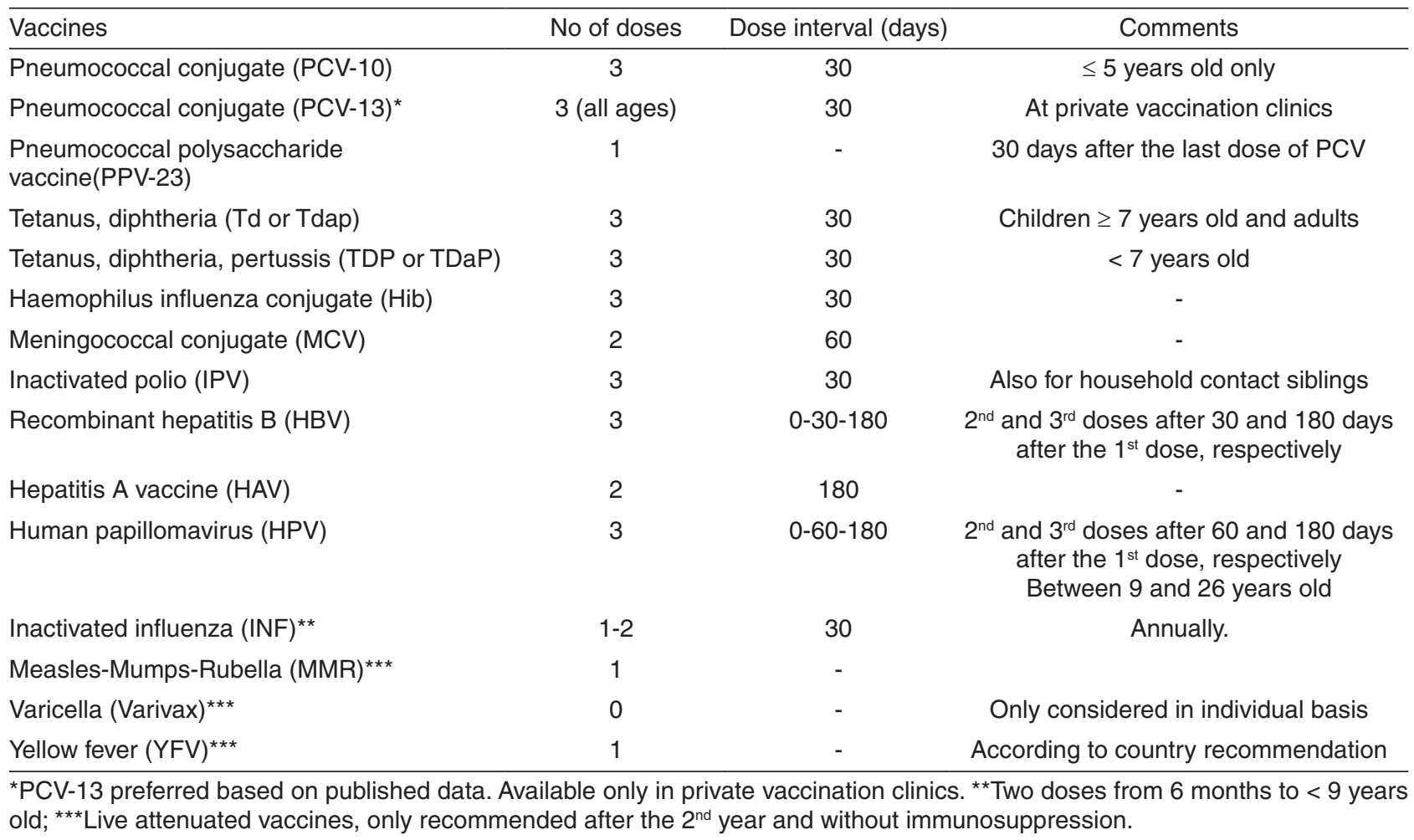


Table 2 - Differences in CRIE and IDSA revaccination schedules proposed to HSCT recipients

\begin{tabular}{|c|c|c|}
\hline Vaccines & $\begin{array}{l}\text { CRIE } 2014 \\
\text { No of doses }\end{array}$ & $\begin{array}{l}\text { IDSA Guidelines } 2013 \\
\text { No of doses }\end{array}$ \\
\hline Pneumococcal conjugate (PCV-10) & 3 ( $\leq 5$ years-old only) & 0 \\
\hline Pneumococcal conjugate (PCV-13) & 0 & 3 (all ages) \\
\hline Pneumococcal polysaccharide vaccine(PPV-23) & 2 & 1 \\
\hline Tetanus, diphtheria (Td) & 3 & 3 \\
\hline Acellular (DTPa) (<7 yr) & 3 & 3 \\
\hline Haemophilus influenza conjugate (Hib) & 3 & 3 \\
\hline Meningococcal C conjugate (MCV) & 1 & 2 \\
\hline Inactivated polio (IPV) & 3 & 3 \\
\hline Recombinant hepatitis B (HBV) & 3 & 3 \\
\hline Hepatitis A vaccine (HAV) & 2 & Idem to general population \\
\hline Human papillomavirus (HPV) & 0 & $\begin{array}{c}3 \text { (female aged } 11-26 \text { yr and HPV4 vaccine } \\
\text { for males aged } 11-26 \mathrm{yr} \text { ) }\end{array}$ \\
\hline Inactivated influenza (INF)* & 1-2 (annually) & 1-2 (annually) \\
\hline Measles-Mumps-Rubella (MMR) ${ }^{\star *}$ & 2 & 2 \\
\hline Varicella $\left(\right.$ Varivax) $^{\star \star}$ & 2 & 2 \\
\hline Yellow fever $(Y F V)^{\star *}$ & 1 & Idem to general population \\
\hline
\end{tabular}

*Two doses if $<9$ years of age; ** Live vaccines, only recommended after the $2^{\text {nd }}$ year and without immunosuppression

end of their revaccination process. Group 2 consisted of 50 HSCT recipients (41\%) at a median of 138 days after HSCT (range 94-462), who were close to start the revaccination program. After a brief explanation, patients were referred to the vaccination centers.

\section{Live attenuated vaccines}

Patients after the second year of HSCT were not included in the study due to logistical reasons; therefore, delays or problems regarding live attenuated vaccines were not analyzed. Except by measles vaccine, yellow fever (YF) and varicella (chickenpox) vaccines are recommended only in special circumstances. We followed the country recommendation for YF vaccination of patients living in risk areas. Varicella vaccine is only recommended in children in specific situations. For VZV seropositive adults, there is no proven benefit of the vaccine, as many of them have already developed herpes zoster up to the second year of HSCT, when vaccination is safe.

\section{Definitions}

According to our vaccination program, patients are expected to complete the vaccine schedule 8 months after starting revaccination, except by the live attenuated vaccines. By definition, those who did not complete the expected schedule were considered out of step. The main reasons for failures were grouped into the following categories: 1) related to patient compliance; 2) related to HSCT center modifications of previous recommendations; and 3 ) related to errors made by public vaccination centers.

\section{Follow-up}

Copies of the vaccine cards were taken at inclusion and regularly thereafter, to track the progress of revaccination. Patients were prospectively followed up by phone calls, emails, cell phones apps, or personally during medical appointments. Whenever a gap on the vaccination program was encountered or a difficulty was reported, personalized interventions and subsequent evaluations were performed. Interventions always focused on the needs of each patient, and a close contact with the vaccination centers was maintained through phone calls and orientation letters.

\section{Ethical issues}

The study was analyzed by the Ethics Committee of the Amaral Carvalho Foundation and is available at http:// aplicacao.saude.gov.br/plataformabrasil/login.jsf. Patients were informed about the risks and benefits of the research and signed the "Informed consent", according to the 466/12 resolution of the National Health Council. 


\section{Statistical analysis}

Continuous variables were expressed as medians. Comparison of qualitative or categorical variables was analyzed using the chi-square test. Logistic regression analysis was performed to determine the variables associated with delays in the revaccination program (software SPSS version 19.0).

\section{RESULTS}

Characteristics of the patients analyzed in the study are shown in Table 3.

The beginning of the vaccination program occurred at a median of 163 days (ranging from 69 to 489 days) in group 1 and 166 days (114 to 466) in group 2 $(\mathrm{p}=0.35)$.

Eleven from 72 patients (15.3\%) in Group 1 and 11 from 50 in Group $2(22 \%)$ presented pitfalls related to patient compliance $(\mathrm{p}=0.34)$. Forty-one patients in Group 1 (56.9\%), and 24 in Group 2 (48\%) presented pitfalls related to HSCT center modifications of previous recommendations $(\mathrm{p}=0.33)$; and $41(56.9 \%)$ and $25(50 \%)$ patients in Groups 1 and 2, respectively, had pitfalls due to errors made by the vaccination center $(p=0.44)$. In total, 105 HSCT recipients (86\%) presented at least one problem, $63(87.5 \%)$ in Group 1 and $42(84 \%)$ in Group $2(\mathrm{p}=0.58)($ Table 4$)$.

Table 3 - Characteristics of HSCT recipients $(\mathrm{N}=122)$

\begin{tabular}{|c|c|c|c|}
\hline & $\begin{array}{c}\text { Group } 1 \\
\mathrm{~N}(\%)\end{array}$ & $\begin{array}{c}\text { Group } 2 \\
\mathrm{~N}(\%)\end{array}$ & $p$-value \\
\hline No of patients (\%) & $72(59)$ & $50(41)$ & \\
\hline Median age & $36(3-72)$ & $27(1-66)$ & 0.15 \\
\hline \multicolumn{4}{|l|}{ Sex } \\
\hline Female & $26(36.1)$ & $22(44)$ & 0.38 \\
\hline Male & $46(63.9)$ & $28(56)$ & \\
\hline \multicolumn{4}{|l|}{ Region } \\
\hline Midwest & $2(2.8)$ & $3(6)$ & 0.18 \\
\hline Northeast & $18(25)$ & $13(26)$ & \\
\hline North & $2(2.8)$ & $6(12)$ & \\
\hline Southeast & $43(59.7)$ & $26(52)$ & \\
\hline South & $7(9.7)$ & $2(4)$ & \\
\hline \multicolumn{4}{|l|}{ Underlying disease } \\
\hline ALL & $18(25)$ & $13(26)$ & 0.39 \\
\hline AML & $19(26)$ & $10(20)$ & \\
\hline CML & $10(14)$ & $2(4)$ & \\
\hline MM & $5(7)$ & $10(20)$ & \\
\hline Other & $20(28)$ & $15(30)$ & \\
\hline \multicolumn{4}{|l|}{ HSCT type } \\
\hline Allogeneic RD/UD & $52 / 11(72 / 15)$ & $24 / 12(48 / 24)$ & 0.04 \\
\hline Autologous & $9(13)$ & $14(28)$ & \\
\hline \multicolumn{4}{|l|}{ Conditioning regimen } \\
\hline Myeloablative/Non-M & $50 / 18(75 / 25)$ & $45 / 5(90 / 10)$ & 0.03 \\
\hline \multicolumn{4}{|l|}{ ATG use } \\
\hline Yes/No & 6/66 (8.3/91.7) & $38 / 12(24 / 76)$ & 0.01 \\
\hline \multicolumn{4}{|l|}{ Stem cell source } \\
\hline Bone marrow & $38(52.8)$ & $24(48)$ & 0.39 \\
\hline Cord blood & $2(2.8)$ & $0(0)$ & \\
\hline PBSC & $32(44.4)$ & $26(52)$ & \\
\hline
\end{tabular}

$\mathrm{RD}=$ related donor; $\mathrm{UD}=$ unrelated donor; $\mathrm{M}=$ myeloablative 
Table 4 - Problems in the revaccination program according to category and patient group ( $\mathrm{N}=105)$

\begin{tabular}{|c|c|c|c|c|}
\hline Category & Problems & $\begin{array}{c}\text { Group } 1(\mathrm{~N}=63) \\
\mathrm{N}(\%)\end{array}$ & $\begin{array}{c}\text { Group } 2(\mathrm{~N}=42) \\
\mathrm{N}(\%)\end{array}$ & $p$-value \\
\hline \multirow{3}{*}{ Patient compliance } & Lack of commitment & $6(9.5)$ & $2(4.8)$ & 0.36 \\
\hline & Difficulty to contact & $6(9.5)$ & $4(9.8)$ & 0.94 \\
\hline & Misunderstanding of the orientation & $2(3.2)$ & $5(11.9)$ & 0.07 \\
\hline \multirow{4}{*}{ HSCT center } & Delay without justification & $6(9.5)$ & $3(7.1)$ & 0.66 \\
\hline & Delay due to complications & $8(12.7)$ & $7(16.7)$ & 0.56 \\
\hline & Delay due to GVHD & $21(33.3)$ & $5(11.9)$ & 0.01 \\
\hline & Delay due to IS without GVHD & $7(18.9)$ & $6(33.3)$ & 0.23 \\
\hline \multirow{4}{*}{ Vaccination center } & Lack of trained team/poor organization* & $28(44.4)$ & $18(42.9)$ & 0.87 \\
\hline & $\begin{array}{l}\text { Vaccine was properly indicated but not autho- } \\
\text { rized by the vaccination center }\end{array}$ & $10(15.9)$ & $3(7.1)$ & 0.18 \\
\hline & $\begin{array}{l}\text { Patients' perception of lack of commitment from } \\
\text { the health personnel }\end{array}$ & $11(17.5)$ & $10(23.8)$ & 0.42 \\
\hline & $\begin{array}{l}\text { Administration of a not-indicated vaccine that } \\
\text { could represent a risk for the patient }\end{array}$ & $6(9.5)$ & $1(2.4)$ & 0.15 \\
\hline
\end{tabular}

*Various: use of vaccines that should not be applied; team unaware of the procedure to get specific vaccines; vaccine denied due to fear; vaccination denied because the patient "had already been vaccinated in childhood"; inadequate completion of the vaccination cards.

Delays in one or more vaccines were frequently observed $(86 / 105,81.9 \%)$. Table 5 presents the frequency of vaccine delays.

Table 5 - Vaccine delays according to patient group ( $\mathrm{N}=86)$

\begin{tabular}{lccc}
\hline Vaccine & $\begin{array}{c}\text { Group 1 } \\
(\mathrm{N}=57)\end{array}$ & $\begin{array}{c}\text { Group 2 } \\
(\mathrm{N}=29)\end{array}$ & p-value \\
\cline { 2 - 3 } & $\mathrm{N}(\%)$ & $\mathrm{N}(\%)$ & \\
\hline Hib & $29(50.9)$ & $21(72.4)$ & 0.05 \\
MCV & $32(56.1)$ & $3(10.3)$ & $<0.001$ \\
PCV10 & $31(54.4)$ & $9(31)$ & 0.04 \\
HAV & $18(31.6)$ & $2(6.9)$ & 0.01 \\
PPV23 & $16(28.1)$ & $1(3.4)$ & 0.007 \\
IPV & $11(19.3)$ & $3(10.3)$ & 0.28 \\
dT/DTP & $10(17.5)$ & $3(10.3)$ & 0.37 \\
HBV & $6(10.5)$ & $3(10.3)$ & 0.97 \\
\hline
\end{tabular}

Univariate analysis showed that type of transplant, myeloablative conditioning, GVHD, use of immunosuppressive drugs, clinical complications, adverse reactions and lack of patient compliance did not contribute significantly to vaccine delays. The non-authorization of vaccines by the vaccination center was the only variable that had a significant impact on the delay of the revaccination program, as shown in Table 6 .

Concerning to the pneumococcal conjugate vaccine, 19 patients in group $1(26.4 \%)$ and $4(8 \%)$ in group $2(\mathrm{p}=0.01)$ did not get the vaccine because the Brazilian Ministry of Healthy does not allow its use in subjects older than 5 years
Table 6 - Variables associated with vaccine delays $(n=122)$

\begin{tabular}{|c|c|c|c|}
\hline \multirow{2}{*}{ Variable } & \multicolumn{2}{|c|}{ Vaccine delay } & \multirow{2}{*}{$p$-value } \\
\hline & Yes (\%) & No (\%) & \\
\hline \multicolumn{4}{|l|}{ Type of HSCT } \\
\hline Allogeneic & $72(72.7)$ & $27(27.3)$ & 0.26 \\
\hline Autologous & $14(60.9)$ & $09(39)$ & \\
\hline \multicolumn{4}{|c|}{ Mieloablative conditioning } \\
\hline Yes & $56(74.7)$ & $19(25.3)$ & 0.44 \\
\hline No & $16(66.7)$ & 08 (33.3) & \\
\hline \multicolumn{4}{|c|}{ Graft versus host disease } \\
\hline Yes & $24(77.4)$ & $07(22.6)$ & 0.32 \\
\hline No & $62(68.1)$ & $29(31.9)$ & \\
\hline \multicolumn{4}{|c|}{ Immunosuppressive drugs } \\
\hline Yes & $11(68.8)$ & $05(31.3)$ & 0.87 \\
\hline No & $75(70.8)$ & $31(29.2)$ & \\
\hline \multicolumn{4}{|c|}{ Clinical intercurrences } \\
\hline Yes & $13(65)$ & $07(35)$ & 0.55 \\
\hline No & $73(71.6)$ & $29(28.4)$ & \\
\hline \multicolumn{4}{|c|}{ Adverse reactions } \\
\hline Yes & $05(50)$ & $05(50)$ & 0.13 \\
\hline No & $81(72.3)$ & $31(27.7)$ & \\
\hline \multicolumn{4}{|c|}{ Lack of patient compliance } \\
\hline Yes & $08(100)$ & $0(0)$ & 0.06 \\
\hline No & $78(68.4)$ & $36(31.6)$ & \\
\hline \multicolumn{4}{|c|}{ Vaccine not authorized } \\
\hline Yes & $13(100)$ & $0(0)$ & 0.01 \\
\hline No & $73(67)$ & $36(33)$ & \\
\hline
\end{tabular}


according to the product label. In two patients, one in group $1(1.4 \%)$ and one in group $2(2 \%)$, the vaccination center considered that the PPV23 was enough and did not authorize the PCV ( $\mathrm{p}=0.79)$. Only four $(5.6 \%)$ and one $(2 \%)$ patients in groups 1 and 2, respectively, were given a justification letter on the non-vaccination for PCV by the vaccination center $(\mathrm{p}=0.33)$. The refusal of pneumococcal vaccine was not uniform, as some centers applied the vaccine without questioning.

Advisory intervention was necessary in 46 episodes in Group 1 (63.9\%) and 23 in Group 2 (46\%) ( $\mathrm{p}=0.05)$. Results of the intervention did not differ significantly among groups and were partially succesful in $30(65.2 \%)$ of Group 1, with total resolution observed in 17 of them (37\%). Similarly, partial success was achieved in 18 patients $(78.3 \%)$ from Group 2, with total resolution of the problems in 9 of them $(39 \%)$.

\section{DISCUSSION}

Our study describes the pitfalls encountered by HSCT recipients who performed the revaccination schedule at their hometowns.

Current revaccination schedules include numerous vaccines, with different number and specific intervals between doses that should be managed to optimize the frequency of patient visits to the vaccination center, reflecting the program complexity. In addition, clinical complications may occur during patient's follow-up and a trained team of health professionals is essential to evaluate the real need of vaccine postponing. Any rupture in this chain results in delay in the revaccination program.

Indeed, the main difficulty encountered in our study was vaccination delays (81.9\%). In general, lack of patient compliance contributed less to revaccination pitfalls (around 20\%) than the issues related to the HSCT unit or the vaccination centers (more than 50\%).

Concerning the HSCT center, a trained nurse proved to be an ideal supervisor for the revaccination program and, along with the transplant infectious disease (TID) doctor, may organize the program and disseminate updated information about vaccine protocols among the HSCT team. Tracking program progress can be made through vaccination cards, phone calls or text messages, Facebook notes, among other initiatives as suggested by some authors ${ }^{15}$.

Constant monitoring is the key to a successful revaccination program. Our study showed that patients who were prospectively monitored by a trained nurse needed significantly less intervention than the group who had already started their revaccination process (46\% and 64\%, respectively, $\mathrm{p}=0.05$ ). Advisory intervention by the nurse and the TID doctor resulted in partial or total resolution of the problems, in around $65 \%$ and $37 \%$, respectively.

GVHD is a frequent reason reported by the HSCT team to postpone vaccines. In 105 patients who had problems in their vaccination schedule, GVHD delayed vaccination in $24.7 \%$ of them. Group 1 accounted with the majority of the delays (33\%) probably because those patients had already started the vaccine program before inclusion in the study. The advisory supervision by the nurse conducting the study significantly decreased the delays due to GVHD in Group 2 , since the patients were followed from the beginning of the protocol (Table 4, $\mathrm{p}=0.01$ ).

Postponing vaccination due to GVHD seems unjustified, as guidelines do not recommend, except for live vaccines ${ }^{2,9,10}$. In addition, there is no evidence of exacerbation of chronic GVHD after use of inactivated vaccines ${ }^{16}$. Nevertheless, a survey conducted by Hudspeth et al. ${ }^{9}$ demonstrated that most of the surveyed centers (59\%) delayed not only live virus vaccines, but also inactivated vaccines in the presence of GVHD $^{9}$. Another study evaluating the vaccination practices for patients with GVHD showed that $30 \%$ of the transplantation centers delayed all vaccines, $30 \%$ delayed only the live vaccines and $39 \%$ delayed all vaccines except for influenza and/or pneumococcal vaccine ${ }^{12}$.

It is known that GVHD and its treatment may decrease vaccine responses to T-cell and antibodies ${ }^{2,3,10,17,18}$ and that is the main excuse used by the HSCT team to postpone vaccination. A more recent communication from the International Consensus Conference on Clinical Practice in chronic GVHD proposed the postponement of vaccinations for up to 3 months in adult patients, if they are receiving three or more immunosuppressive agents for the treatment of $\mathrm{GVHD}^{19}$. However, some of these patients may respond to vaccines. As the recommended vaccines (except for the live ones) are safe in the GVHD scenario, some authors recommend to measure specific antibody levels before and after vaccination to evaluate protection and the need for booster doses ${ }^{2,9}$.

Some authors have found that allogeneic HSCT recipients have frequent delays in the revaccination program due to recurrent clinical complications during follow-up ${ }^{12}$. In our study, the type of HSCT was not associated with vaccine delays. Allogeneic HSCT recipients presented similar rates of vaccine delay ( $72 \%$ ), in comparison to autologous $(61 \%, \mathrm{p}=0.26)$. Other authors observed that patients undergoing autologous or allogeneic transplants presented different problems causing missed and/or delayed vaccination, although no statistical comparison was made between groups ${ }^{15}$.

A variety of immunization protocols have been proposed. In 1995, a survey developed among HSCT 
centers demonstrated that vaccines were improperly used, protocols were very different among centers and just few centers used multiple vaccine doses ${ }^{9}$. Thus, it is clear that the acceptance of the recommended revaccination program varies according to the center and, in some of them, up to $48 \%$ of the patients have no appropriate reason to be out of step with their vaccination schedule ${ }^{15}$. Fortunately, the vaccination protocol seems to be accepted by the HSCT team at Amaral Carvalho Foundation. Only a small number of patients in both groups had vaccine delays without reason, 6 in group $1(14.3 \%)$ and 5 in group $2(18.5 \%$, $\mathrm{p}=0.63$ ).

Concerning to the vaccination centers, the most frequent problem found was the lack of a properly trained team and/or poor organization. Health personnel working at the Basic Health Units do not seek guidance from the CRIE, as how to obtain special vaccines and specific immunoglobulin, or how to manage adverse situations. CRIEs should be the first to be consulted in these cases. In our study, more than $40 \%$ of the problems related to the vaccination center fell in this category. Moreover, $9.5 \%$ of the patients in group 1 and $2.4 \%$ in group 2 received live vaccines, which were incorrectly indicated considering the post-transplantation period. Health professionals working in this scenario should have adequate training and frequent expert supervision to clarify doubts and reduce errors that can be life threatening.

Unfortunately, the cost effectiveness of the immunization program provided by the Brazilian Ministry of Health may result disappointing if properly trained health professionals were not available. Other authors analyzing children's vaccination records and the health service at Botucatu city, São Paulo State, Brazil, observed that approximately $30 \%$ of the studied population were not informed about the administered vaccine, the next vaccines to be scheduled, the possibility of adverse reactions, or they received inadequate information. The lack of orientation was the main cause of delayed vaccines, identified in $60 \%$ of the cases $^{20}$.

In our study, the highest proportion of delay was found with $\mathrm{MCV}$ in patients from group 1 and with Hib in patients from group 2 . The vaccine against meningitis $C$ has been recently incorporated to the CRIE's vaccination schedule as recommended to HSCT recipients, justifying the delay in $32(56.1 \%)$ of the patients in Group $1^{13}$. In previous international guidelines, meningococcal vaccine was just recommended if indicated ${ }^{2,4}$. As patients in group 2 initiated the process using the updated protocol, only a few delays in MCV vaccine were observed in this group. The delay in carrying out Hib vaccine in patients from group 2 was related to an interruption in vaccine distribution by the National Laboratory, Bio-Manguinhos/Fiocruz, since
November 2014 (personal communication by Carla Magda Allan Santos Domingues), while most of the patients in group 1 had already completed this stage of the protocol.

Although less frequent than the delays observed with MCV and Hib, the pneumococcal vaccines deserve special comments. The first licensed conjugate pneumococcal vaccine was PCV7 (Prevnar, Pfizer, Inc. New York), which offers protection against serotypes $4,6 \mathrm{~B}, 9 \mathrm{~V}, 14,18 \mathrm{C}, 19 \mathrm{~F}$ and $23 \mathrm{~F}^{21}$. This vaccine was proven to be immunogenic and safe in both child and adult HSCT recipients ${ }^{22,23}$. The 10-valent pneumococcal vaccine (Synflorix, GSK, Brentford, UK) was also licensed in Europe, and uses different carrier proteins compared to PCV7 and offers seroprotection against three additional serotypes $(1,5$, and $7 F)$. The PCV10 was never tested in transplant patients ${ }^{24}$.

In 2010, the new 13-valent pneumococcal vaccine (Prevnar 13, Pfizer, Inc., New York), was already approved and being tested in HSCT recipients. At that moment, the recommendation has been to use PCV13, if the 7-valent vaccine was no longer available ${ }^{24}$. The study evaluating PCV13 in HSCT recipients has been recently published and confirmed the safety and effectiveness of the vaccine ${ }^{11}$.

In Brazil, the PCV10 was introduced in the national immunization program in 2010 for children younger than 2 years old ${ }^{14}$, and then included in the vaccination schedule for immunocompromised patients up to 5 years (off-label), as a substitute for PCV7. The PCV13 is not offered by the Brazilian Ministry of Health, and is only available in private vaccination clinics.

In our study, the delay observed in pneumococcal vaccination was due to the refusal by the vaccination center to vaccinate adult patients. The Brazilian Ministry of Health considers the PCV10 in adults "off-label" as the product label indicates its use in children up to 5 years ${ }^{25}$. Unfortunately, since the PCV7 is no longer available, and the PCV13 is currently not included in the national program, an immediate change in this scenario seems unlikely and adult HSCT recipients can only receive the PPV23.

However, some studies have shown that the best response to pneumococcal vaccine is observed when conjugate vaccines are used before the polysaccharide vaccine. de Roux et al. ${ }^{22}$ compared the immunogenicity and safety of PCV7 with PPV in adults immunized at study entry and receiving a second dose of PCV7 or PPV after one year. The authors demonstrated that the highest responses occurred in the group receiving 2 doses of the conjugate vaccine, and the lowest responses were observed in the PPV/PCV7 group.

Cordonnier et al..$^{23}$ used the PCV7 vaccine in HSCT recipients with a median age of 37 years old (range 7 to 59). Response to PCV7 given 3 months after transplantation 
was not inferior to the late start at 9 months of HSCT (79\% in early and $82 \%$ in late vaccination). They also studied the effects of PPV23 vaccination after PCV7 in HSCT recipients, and showed that among patients who did not have a response after three doses of PCV7, $41 \%$ responded to the PCV7 antigens after receiving a dose of PPV23. Therefore, PPV23 may not only confer protection to 16 extra serotypes, but may also boost the response to PCV7 serotypes. Thus, authors recommended the use of 3 doses of PCV7 at monthly intervals, starting 3 months after HSCT transplantation, followed by one dose of PPV23.

Recently, the same authors using 4 doses of PCV13 (3 doses with one month interval and a $4^{\text {th }}$ dose after 6 months) in pediatric and adult allogeneic recipients, identified an increase in antibody levels after 3 doses across all PCV 13 serotypes, with a significant decline in the next six months but, a new increase after the $4^{\text {th }}$ dose. The use of PPV 23 one month after the fourth dose usually maintained stable the antibody levels, even though an increase in systemic and local adverse reactions may occur ${ }^{11}$.

Finally, the number of doses may also play an important role in vaccination delays. In our study, the vaccine against influenza virus was the only vaccine with no delay. Besides being a single dose vaccine, our institution develops a solid annual program to control respiratory virus transmission, targeting patients, caregivers and health professionals, which includes influenza vaccine campaign, may explain this result ${ }^{26}$

Nelson et al. ${ }^{27}$ evaluated the proper fulfillment of some vaccines that require multiple doses (varicella, hepatitis $\mathrm{A}$, and hepatitis $\mathrm{B}$ vaccine). Completion rates of all doses were higher for hepatitis B vaccine $(55 \%-65 \%$ in most age groups) within a year, whereas compliance with hepatitis A and varicella vaccines was lower $(40 \%-50 \%$ for most age groups). The authors observed that compliance with multiple doses was low, particularly among adolescents, young adults and low socioeconomic level individuals.

The present study demonstrated that no matter the problem identified, the main consequence would be the delay in the revaccination program. The refusal in administrating the vaccine by the vaccination center was identified as the major reason for delays. The conjugate pneumococcal vaccine should be urgently made available to adult HSCT recipients since there is scientific evidence of its safety and effectiveness.

Vaccination guidelines have been developed and updated; however, the Brazilian revaccination program needs to be adjusted and the Basic Health Units need to improve relationship with the CRIE, because many HSCT recipients remain unvaccinated, are vaccinated late, or undergo an incomplete vaccination schedule.
All efforts should be made to assure that HSCT recipients have access to a safe and complete revaccination program. Our study showed that tailored follow-up performed by nurses and TID doctors helped to overcome the difficulties faced in this process.

\section{ACKNOWLEDGEMENTS}

The authors thank the health professionals of the HSCT Program of the Amaral Carvalho Foundation, as well as patients and their relatives, without whose collaboration this study would not be performed.

\section{REFERENCES}

1. Tomblyn M, Chiller T, Einsele H, Gress R, Sepkowitz K, Storek $\mathrm{J}$, et al. Guidelines for preventing infectious complications among hematopoietic cell transplantation recipients: a global perspective. Biol Blood Marrow Transplant. 2009;15:1143238.

2. Ljungman P, Cordonnier C, Einsele H, Englund J, Machado CM, Storek J, et al. Vaccination of hematopoietic cell transplant recipients. Bone Marrow Transplant. 2009;44:521-6.

3. Machado CM. Reimmunization after hematopoietic stem cell transplantation. Expert Rev Vaccines. 2005;4:219-28.

4. Johnston BL, Conly JM. Immunization for bone marrow transplant recipients. Can J Infect Dis. 2002;13:353-7.

5. Ljungman P, Lewensohn-Fuchs I, Hammarström V, Aschan $\mathrm{J}$, Brandt L, Bolme P, et al. Long-term immunity to measles, mumps, and rubella after allogeneic bone marrow transplantation. Blood. 1994;84:657-63

6. Ljungman P, Aschan J, Barkholt L, Broliden PA, Gustafsson B, Lewensohn-Fuchs I, et al. Measles immunity after allogeneic stem cell transplantation; influence of donor type, graft type, intensity of conditioning, and graft-versus host disease. Bone Marrow Transplant. 2004;34:589-93.

7. Machado CM, Gonçalves FB, Pannuti CS, Dulley FL, De Souza VA. Measles in bone marrow transplant recipients during an outbreak in São Paulo, Brazil. Blood. 2002;99:83-7.

8. Prager J, Thilo W, Hermann J, Fuchs D, Zintl F. Kinetics of vaccination antibodies against tetanus toxoid, diphtheria toxoid, measles virus, poliomyelitis virus and pneumococcus after allogenic and autologous bone marrow transplantation and booster vaccination. 2: Kinetics of vaccination antibodies against diphtheria toxoid after allogenic and autologous bone marrow transplantation. Kinderarztl Prax. 1992;60:195-8.

9. Hudspeth MP, Hill TN, Lewis JA, Van Meter E, Ragucci D. Posthematopoietic stem cell transplant immunization practices in the pediatric blood and marrow transplant consortium. Pediatr Blood Cancer. 2010;54:970-5.

10. Lee DG. Vaccination of hematopoietic stem cell transplantation 
recipients: perspective in Korea. Infect Chemother. 2013;45:272-82.

11. Cordonnier C, Ljungman P, Juergens C, Maertens J, Selleslag D, Sundaraiyer $\mathrm{V}$, et al. Immunogenicity, safety, and tolerability of 13 -valent pneumococcal conjugate vaccine followed by 23-valent pneumococcal polysaccharide vaccine in recipients of allogeneic hematopoietic stem cell transplant aged $\geq 2$ years: an open-label study. Clin Infect Dis. 2015;61:313-23.

12. Ariza-Heredia EJ, Gulbis AM, Stolar KR, Kebriaei P, Shah DP, McConn KK, et al. Vaccination guidelines after hematopoietic stem cell transplantation: practitioners' knowledge, attitudes, and gap between guidelines and clinical practice. Transpl Infect Dis. 2014; 16:878-86.

13. Brasil. Ministéro da Saúde. Secretária de Vigilância em Saúde. Departamento de Vigilância Epidemiológica. Manual dos centros de referência para imunobiológicos especiais. $4^{\mathrm{a}} \mathrm{ed}$. Brasília: Ministério da Saúde; 2014. [cited 2017 Aug 3]. Available from: http://i9projetos.com.br/infectologiaemfoco_ blog/wp-content/uploads/2014/11/manual_CRIE_7out14.pdf

14. Rubin LG, Levin MJ, Ljungman P, Davies EG, Avery R, Tomblyn M, et al. 2013 IDSA clinical practice guideline for vaccination of the immunocompromised host. Clin Infect Dis. 2014;58:e44100.

15. Lerchenfeldt SM, Cronin SM, Chandrasekar PH. Vaccination adherence in hematopoietic stem cell transplant patients: a pilot study on the impact of vaccination cards and reminder telephone calls. Transpl Infect Dis. 2013;15:634-8.

16. Ljungman P, Engelhard D, de la Cámara R, Einsele H, Locasciulli A, Martino R, et al. Vaccination of stem cell transplant recipients: recommendations of the Infectious Diseases Working Party of the EBMT. Bone Marrow Transplant. 2005;35:737-46.

17. Machado CM. Reimmunization after bone marrow transplantation - current recommendations and perspectives. Braz J Med Biol Res. 2004;37:151-8.

18. Patel SR, Ortín M, Cohen BJ, Borrow R, Irving D, Sheldon $\mathrm{J}$, et al. Revaccination with measles, tetanus, poliovirus, Haemophilus influenzae type B, meningococcus $\mathrm{C}$, and pneumococcus vaccines in children after hematopoietic stem cell transplantation. Clin Infect Dis. 2007;44:625-34.
19. Hilgendorf I, Freund M, Jilg W, Einsele H, Gea-Banacloche J, Greinix H, et al. Vaccination of allogeneic haematopoietic stem cell transplant recipients: report from the International Consensus Conference on Clinical Practice in Chronic GVHD. Vaccine. 2011;29:2825-33.

20. Molina AC, Godoy I, Carvalho LR, Caldas Jr AL. Situação vacinal infantil e características individuais e familiares do interior de São Paulo. Acta Sci Health Sci. 2007;29:99-106.

21. Klok RM, Lindkvist R, Ekelund M, Farkouh RA, Strutton DR. Cost-effectiveness of a 10- versus 13 -valent pneumococcal conjugate vaccine in Denmark and Sweden. Clin Ther. 2013;35:119-34.

22. de Roux A, Schmöle-Thoma B, Siber GR, Hackell JG, Kuhnke A, Ahlers N, et al. Comparison of pneumococcal conjugate polysaccharide and free polysaccharide vaccines in elderly adults: conjugate vaccine elicits improved antibacterial immune responses and immunological memory. Clin Infect Dis. 2008;46:1015-23.

23. Cordonnier C, Labopin M, Chesnel V, Ribaud P, De La Camara R, Martino R, et al. Randomized study of early versus late immunization with pneumococcal conjugate vaccine after allogeneic stem cell transplantation. Clin Infect Dis. 2009;48:1392-401.

24. Ljungman P, Small TN. Update to Vaccination Guidelines. Biol Blood Marrow Transplant. 2010;16:1608-9.

25. Vacina pneumocócica 10 valente (conjugada) [package insert]. Rio de Janeiro: Instituto de Tecnologia em Imunobiológicos - BIO-MANGUINHOS: Fundação Oswaldo Cruz; 2016.

26. Santos AC, Perilio L, Zerbinati RM, Souza MO, Colturato VA, Souza MP, et al. Respiratory symptom surveillance to optimize the detection of community respiratory virus in hematopoietic stem cell transplant (HSCT) recipients: preliminary results. In: $35^{\text {th }}$ Annual Meeting of the European Group for Blood and Marrow Transplantation, 2009, Sweden. Bone Marrow Transplant. 2009;43 Suppl 1:S63-4.

27. Nelson JC, Bittner RC, Bounds L, Zhao S, Baggs J, Donahue JG, et al. Compliance with multiple-dose vaccine schedules among older children, adolescents, and adults: Results from a vaccine safety datalink study. Am J Public Health. 2009;99 Suppl 2:S389-97. 